\title{
A Soil Emergence Trap for Collections of Phlebotomine Sand Flies
}

\section{Cláudio Casanova}

Laboratório de Parasitoses por Flagelados, Superintendência de Controle de Endemias do Estado de São Paulo, Rua Afonso Pessini 86, 13840-000 Mogi Guaçu, SP, Brasil

The identification of breeding sites of sand flies is of great epidemiological interest. A soil emergence trap for investigating potential sand fly breeding sites is described. The trap was tested in two rural areas in the Mogi Guaçu River Valley where the American cutaneous leishmaniasis is an endemic disease. Seventy-three sand fly individuals of three species, Lutzomyia intermedia s. 1., L. whitmani and L. pessoai, were collected on the forest floor and peridomicile.

Key words: soil emergence trap - sand fly breeding sites - Lutzomyia species

Soil emergence traps are the main indirect method employed for the identification of natural breeding sites of sand flies. Available trap designs vary in features such as size, shape, material and technique of trapping the emerging sand flies (Rutledge \& Ellenwood 1975, Arias \& Freitas 1982, Bettini et al. 1986, Vieira et al. 1999). The trapping techniques used in most of these traps require a high frequency of visits (1-3 days) to remove the insects. In this note, I describe a cheap trap that is easy to construct and to install. The removal of trapped sand flies is simple. One of the main advantages of this trap is that it needs to be examined only every 15 days.

The trap is made up of a dark round plastic basin measuring $45 \mathrm{~cm}$ diameter and $15 \mathrm{~cm}$ height (Figure). A $6 \mathrm{~cm}$ diameter hole is cut at the base of the basin, where a PVC connection is fitted. This connection is $2 \mathrm{~cm}$ tall and $7.5 \mathrm{~cm}$ diameter. Then, a 7 $\mathrm{cm}$ tall PVC tube is inserted in this connection and covered on the top with fine-mesh gauze to prevent escape of the sand flies. The inner surface of this tube is partially covered with a $3 \times 22 \mathrm{~cm}$ adhesive paper (Fly - Catcher "The Stable", Silva Made in Sweden, distributed in Brazil by "New Products - Comercial Agrícola e Veterinária"),

This work was supported by funds from Convênio 001/ 98 Superintendência de Controle de Endemias do Estado de São Paulo and Companhia Energética de São Paulo, Companhia de Geração de Energia Elétrica Tietê. Fax: +55-19-3861.1233. E-mail: clcasanova@ig.com.br Received 26 April 2000

Accepted 18 October 2000 which acts as a sticky trap for the newly emerged sand flies. To protect the collecting tube from the weather, an $8 \mathrm{~cm}$ tall transparent, perforated plastic container is inverted over the tube and fitted on the container's base. The basin is fixed to the ground by three poles and sealed with earth or litter around the rim to prevent escape or entrance by flies. Emerging sand flies, attracted to the light filtered by the fine-mesh gauze on the upper end of the collecting tube, get stuck on the adhesive paper while trying to fly out. The collecting tube can be replaced without removing the basin. The adhesive paper can be removed and examined under a stereomicroscope for the presence of sand flies. The flies should be carefully removed with a brush soaked in xylol and kept for $2 \mathrm{~h}$ in a vial with xylol to remove the glue.

Since the flies are caught on sticky paper, the collector tubes may be left for periods as long as 23 days. However, because of fungal growth that may destroy the flies we recommend that the cylinders be changed every 15 days. The adhesive paper may be reused if they do not become overload with soil litter particles or other insects.

Forty of these traps were employed to investigate potential sand fly breeding sites in two rural areas in the Mogi Guaçu River Valley, where the American cutaneous leishmaniasis (ACL) is an endemic disease. The two areas, one located in the municipality of Mogi Mirim (22 $25^{\prime}$ 'S and $46^{\circ} 57^{\prime} \mathrm{W}$ ) and the other in the municipality of Conchal $\left(22^{\circ} 18^{\prime} S\right.$ and $\left.47^{\circ} 13^{\prime} \mathrm{W}\right)$, consist of ranches that are close to the secondary gallery forests of the Mogi Guaçu River.

Emergence trap collections were done from April to June 1999, at eight sites in the peridomicile 


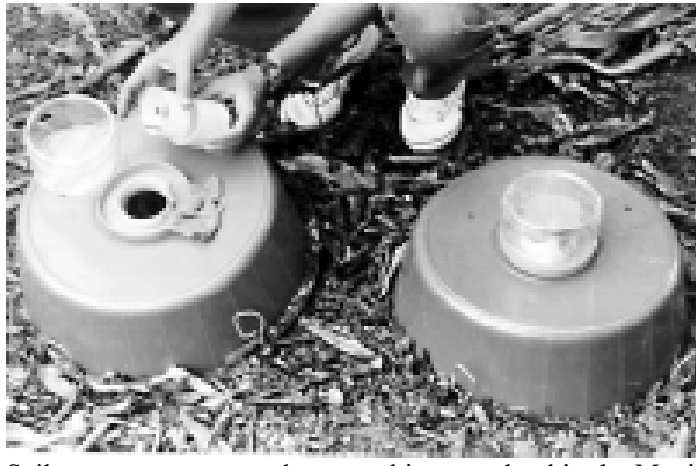

Soil emergence trap on the ground in an orchard in the Mogi Mirim area. Right: one trap installed. Left: putting adhesive paper in the inner surface of the collecting tube

of a Mogi Mirim ranch (two traps inside chicken sheds, four near chicken sheds, and two on the ground in an orchard), and another eight sites in forest floor litter, approximately $500 \mathrm{~m}$ from the ranch.

During August, October and November 1999, emergence trap collections were made at a ranch in Conchal. Eight sites were in the peridomicile area under trees that are used as chicken sheds, and 16 sites in forest floor litter less than $100 \mathrm{~m}$ from the nearest house.

The trapping period in the above series varied from 14 to 39 days and collections from the traps (with replacement of the collecting tube) were made at intervals varing from 6 to 23 days. The Table shows the number of sand flies collected in both areas as well as in the two kinds of habitats investigated.

Lutzomyia intermedia s. $l$. was the predominant species, followed by L. whitmani and L. pessoai, in the peridomicile of Mogi Mirim area, and the only species captured in the peridomicile and forest habitats in the Conchal area.

One advantage of employing emergence traps to detect sand fly breeding sites is that they allow estimates of absolute population densities. Considering the period of investigation and the number and sampling area of the traps, the estimated production of $L$. intermedia s. $l$. in the litter of the forest floor in Conchal is of 24 sand flies per $100 \mathrm{~m}^{2}$ per day. In the same kind of habitat, but using cubic or pyramidal traps, Rutledge and Elenwood (1975) in Panama, and Arias and Freitas (1982) in Brazil estimated, to the total of sand flies species captured, a production of 24.4 and 4.1 sand flies per $100 \mathrm{~m}^{2}$ per day, respectively. The estimate of production in the peridomicile in the Mogi Mirim and Conchal areas were of 38.7 and 32.6 sand flies per $100 \mathrm{~m}^{2}$ per day, respectively. The greater absolute emergence rate of sand flies in the peridomicile may be explained by the fact that more traps were put in shaded areas where there was a lot of decomposing organic material close to the chicken sheds. Finding phlebotomine species that are implicated with the transmission of the ACL in the southeastern region of Brazil, in habitats very near to human dwellings, gives weight to the maintenance of the secondary transmission cycle that occurs outside the forest.

The data on emergence rates obtained in this study indicate that the tested trap efficiently detects sand fly breeding sites. The difficulty in finding breeding sites of sand flies has oriented the control measures only to the adult stage of the insect. However, the results of the present investigation point out to perspectives of studies either on the biology and ecology of immature forms or on formulating more appropriate and effective control measures. In this study, the biological complexity and the extensive area of the forest investigated make it impracticable to use control measures on immature forms in this habitat. However, in the peridomicile the physical change of the habitat or the use of chemical control of sand flies on the egg, larval and pupal stages is worthy to be evaluated.

\section{TABLE}

Distribution of Lutzomyia species collected using emergence traps, by habitat investigated (peridomicile and forest litter), in two municipalities of the Valley of Mogi Guaçu River (Mogi Mirim and Conchal), from April to November 1999

\begin{tabular}{|c|c|c|c|c|c|c|c|c|}
\hline \multirow{3}{*}{ Species } & \multicolumn{4}{|c|}{ Mogi Mirim } & \multicolumn{4}{|c|}{ Conchal } \\
\hline & \multicolumn{2}{|c|}{ Peridomicile } & \multicolumn{2}{|c|}{ Forest litter } & \multicolumn{2}{|c|}{ Peridomicile } & \multicolumn{2}{|c|}{ Forest litter } \\
\hline & Male & Female & Male & Female & Male & Female & Male & Female \\
\hline L. intermedia s. $l$. & 16 & 6 & - & - & 16 & 1 & 11 & 14 \\
\hline L. whitmani & 7 & - & - & - & - & - & - & - \\
\hline L. pessoai & 2 & - & - & - & & - & - & \\
\hline Total & 25 & 6 & - & - & 16 & 1 & 11 & 14 \\
\hline
\end{tabular}




\section{ACKNOWLEDGMENTS}

To Dr Jeffrey Shaw and Dr Marcio Zikan for the helpful comments on this paper and Mrs Maricy Marino for her support.

\section{REFERENCES}

Arias JR, Freitas RA 1982. On the vectors of cutaneous leishmaniasis in the Central Amazon of Brazil. 4. Sand fly emergence from a "terra firme" forest floor. Acta Amazon 12: 609-611.

Bettini S, Contini C, Atzeni MC, Tocco G 1986. Leishmaniasis in Sardinia. I. Observations on a larval breeding site of Phlebotomus perniciosus, Phleboto- mus perfiliewi perfiliewi and Sergentomyia minuta (Diptera: Psychodidae) in the canine leishmaniasis focus of Soleminis (Cagliari). Ann Trop Med Parasitol 80: 307-315.

Rutledge LC, Ellenwood DA 1975. Production of phlebotomine sandflies on the open forest floor in Panama: the species complement. Environ Entomol 4: 71-77.

Vieira VP, Ferreira AL, Falqueto A 1999. Pesquisa de criadouros de flebotomíneos no ambiente peridomiciliar, em área endêmica de leishmaniose tegumentar (LT) no Estado do Espírito Santo. Rev Soc Bras Med Trop 32 (Supl. 1): 31-32. 